\title{
Prevalence of Undernutrition and Associated Factors among Adult People Living with HIV/AIDS and on ART in Achefer District, North West Ethiopia: Cross-Sectional study
}

Yosef Wasihun ( $\sim$ yosef511943@gmail.com )

Bahir Dar University

Mengistu Yayehrad

North Achefer Health Office, Ethiopia

Samuel Dagne

Bahir Dar University

Yonatan Menber

Bahir Dar University

Tadesse Awoke

University of Gondar

Girma Nega

Bahir Dar University

\section{Research}

Keywords: Prevalence, under nutrition, PLWHIV, ART, Ethiopia

Posted Date: August 4th, 2020

DOI: https://doi.org/10.21203/rs.3.rs-39316/v1

License: (c) This work is licensed under a Creative Commons Attribution 4.0 International License.

Read Full License 


\section{Abstract}

Introduction: Human immunodeficiency virus/ Acquired immunodeficiency syndrome (HIV/AIDS) is one of the major public health Problem worldwide and its epidemic is occurring in populations where malnutrition is already endemic. Ethiopia is among the countries most affected by under nutrition and HIV epidemic in the region. The objective of this study was to determine the prevalence of under nutrition and associated factors among adult people living with HIV/AIDS and on ART in Achefer Woreda, North West Ethiopia.

Methods and Materials: Institution based cross sectional study design was used and conducted from May 01-30/2015. Systematic random sampling technique was used to select the study subjects and the data was collected using clinical assessment, measurements and interviewer administered questionnaire. To identify independent predictors of under nutrition of adult people living with HIV/AIDS and on ART, we performed multivariable logistic regression analyses using SPSS version 20 with $\mathrm{Cl}$ of $95 \%$ at $\mathrm{p}$-value $<0$. 05.

Result: Three hundred fifty HIV/AIDS on ART patients were included in the study. The overall prevalence of under nutrition was $26.9 \%$ and females were most affected 57 (18.1\%). Anti-retroviral treatment duration of 6-11months and 12-24 months $(A O R=4.72,95 \% \mathrm{Cl}, 1.10-20.35)$ and $(\mathrm{AOR}=6.93,95 \% \mathrm{Cl}$, 1.614-29.754) respectively, WHO Stage two and three $(\mathrm{AOR}=3.01,95 \% \mathrm{Cl}, 1.061-8.534)$ and $(\mathrm{AOR}=$ $12.56,95 \% \mathrm{Cl}, 4.27-36.99)$ respectively and dietary counseling ( $\mathrm{AOR}=0.20,95 \% \mathrm{Cl}, .05-.78)$ were significantly associated with under nutrition.

Conclusion and Recommendation: Undernutrition was high in PLWHA and on ART. ART duration, WHO clinical staging, presence of eating problem and dietary counselling were the predictors for under nutrition of HIV patients on ART. Only increasing access to ART can't solve problem of under nutrition, therefore nutrition therapy and support, site expansion also as an accessory to the initiation of ART should be considered.

\section{Introduction}

The emergence of HIV epidemic is one of the biggest public health challenges the world has ever seen in recent history. Recently, although the global incidence of HIV infection has stabilized and begun to decline in many countries. But, countries in the SSA are home to the majority of all people living with HIV in the world [1-3].

In SSA HIV/AIDS and malnutrition are both highly prevalent. A significant proportion of patients who require ART are malnourished because of Low energy intake combined with increased energy demands due to HIV. Food insecurity can lead to macronutrient and micronutrient deficiencies, which can affect both vertical and horizontal transmission of HIV, and contribute to immunologic decline; poor treatment outcome and increased morbidity and mortality [4-7]. Ethiopia is second most populous countries in Africa with estimated population of more than 95.5 million of which $32.7 \%$ live below the absolute 
poverty line. HIV/AIDS new infection shows that a 25\% decline, but still high. EDHS 2011 data shows an overall prevalence of $1.5 \%$ among the general population and nearly 800,000 are living with HIV $[1,8]$.

There is no single defining pathophysiology to AIDS wasting. However, protein metabolism is abnormal in HIV-infected individuals and there are situations such as severe rapid weight loss, failure to respond to nutrition support and inability to achieve adequate energy intake, in which combined use of anabolic agents may be indicated. Micronutrient deficiencies, body weight loss, and wasting in advanced HIV disease are caused by a similar combination of decreased food intake or chronic food insecurity, catabolic state induced by opportunistic infection (OI) or malignancy, prolonged fever and depressive syndrome. Acute wasting tends to be associated with secondary $\mathrm{OI}$ and chronic wasting is associated with gastrointestinal disease. A decrease in the rate of HIV infection related wasting has been reported in the era of highly active antiretroviral therapy [6, 9-10].

Adequate nutrition increases resistance to infection and disease, improves energy, and thus makes a person more productive. People who are infected with HIV require more nutrients to compensate for poor absorption, adverse drug effects, frequent diarrhea, nausea and recurrent Ols [11-13].

Despite implementing different programs to overcome the problems of HIV/AIDS, Nutrition-related complications remain a challenging issue for HIV-infected patients. Understanding and assessing factors affecting the nutritional status of HIV infected individuals are a vital and timely activities which can be affected by the dietary habit and feeding pattern of a community. The purpose of this study was to determine the prevalence of under nutrition and associated factors of adult people living with HIVAIDS on ART in Achefer Woreda, Ethiopia.

\section{Methods And Materials}

\section{Study design and setting}

Institutional based cross sectional study was conducted to determine the prevalence of under nutrition and associated factors among adult people living with HIV/AIDS and on ART in Achefer Woreda, Ethiopia from May 01-30/2015. Achefer district is one of the 15 districts in West Gojam zone Amhara Region, Ethiopia and has an estimated total population of 391,919. This district is located at $501 \mathrm{~km}$ North-West of Addis Ababa, the capital city of Ethiopia and $55 \mathrm{~km}$ from Bahir Dar Capital City of Amara Regional state. Agricultural products like maize, dagusa, wheat, teff, sorghum and vegetables like mango, banana and orange are cultivated in most parts of the District.

There are a total of 15 health centers (HCs) which provides ART services. There are around 1130 patients on ART and 15 health workers (HWs) who are trained on both adult and pediatric ART providing the service from each HCs. Five of the HCs give plump nut supplementation for ART patients monthly.

\section{Study participants and procedures}


The study population was all selected HIV/AIDS patients who were enrolled to ART care clinic in health centers of the Woreda. The sample size was calculated using single population proportion formula with the following assumption, the prevalence of under nutrition among adult people living with HIV conducted in Gondar 27.8\% (36), with 95\% confidence level and 5\% marginal error, the sample size was 309. By adding $5 \%$ non-response rate the sample size was 325 . The study participants were selected by systematic random sampling technique making a continuous list of subjects from the first to last day of data collection by using registration book. The first participant was selected from first day registration by lottery method and then taking every 3rd individual from the list of clients. Each patient was selected only once, on his/ her first visit, if selected and repeated visits were excluded by recording registration numbers of each participated patients. Those participants aged 18 years and older who were on ART and any treatment duration were included but those critically ill were excluded from the study.

\section{Data collection and measurements}

The data was collected using pre-tested, structured and interviewer administered questionnaire. The questionnaire was prepared first in English and then translated into the local language Amharic and then retranslated back to English by another individual to check consistency. The questionnaire included socioeconomic, demographic and medical factors. Five percent of the questionnaire was pretested in Mecha district which is found $25 \mathrm{~km}$ far from the study area. Four ART nurse data collectors and one health officer supervisor were involved during data collection. Training was given for data collectors and supervisor about the data collection tool, how to collect data and taking consent to have common understandings. The overall data collection process was strictly followed by the principal investigator.

Nutritional status of the participants was screened by measuring height and weight and calculating BMI. Height of the patients was measured using height scale by placing the participants on leveled place for height measurement, and standing upright in the area with bare foot and reading was recorded to the nearest $0.1 \mathrm{~cm}$. Weight of study participants were measured by SECA model 201702201, serial number 5002700130149 with minimum/lightly/clothing and no shoes and the reading was recorded to the nearest $0.1 \mathrm{~kg}$ after taking the average of two measurements. Participants with a BMI of less than $18.5 \mathrm{~kg} / \mathrm{m}^{2}$ considered as undernutrition.

\section{Data Processing and Analysis}

The data was coded, cleaned and entered into SPSS version 23 and analyzed using this software.

The descriptive result was presented using frequency and proportions for all variables and we performed bivariable regression analysis to determine association between factors of undernutrition at $95 \%$ confidence interval and $p$-value of $<0.25$. To identify the independent predictors of undernutrition, we performed multivariable logistic regressions, and variables with $p$-value $<0.05$ were considered as statistically significant predictors of outcome variables. Goodness of fit of the final model was checked using Hosmer and Leme show test of goodness fit.

\section{Results}


A total of 315 patients on ART were included in the study with response rate of $96.9 \%$. Majority of the participants 200 (63.5\%) were females. About 151 (47.9\%) of the patients were in the age group of 2534 years. The mean age of the respondents was 34.97 years with \pm 8.25 SD. (Table -1$)$. 
Table 1

Socio-Demographic Characteristics of Adult People Living with HIV/AIDS on ART at Selected Health Centers of Achefer Woreda, North West

Ethiopia, June 2015, ( $\mathrm{N}=315)$.

\begin{tabular}{|c|c|c|c|}
\hline \multicolumn{2}{|l|}{ Variables } & \multirow{2}{*}{$\begin{array}{l}\text { Frequency } \\
18\end{array}$} & \multirow{2}{*}{$\begin{array}{l}\% \\
5.7\end{array}$} \\
\hline Age & $15-24$ & & \\
\hline & $25-34$ & 151 & 47.9 \\
\hline & $35-44$ & 94 & 29.8 \\
\hline & $>=45$ & 52 & 16.5 \\
\hline \multirow[t]{2}{*}{ Sex } & Male & 115 & 36.5 \\
\hline & Female & 200 & 63.5 \\
\hline \multirow[t]{2}{*}{ Residence } & Urban & 197 & 62.5 \\
\hline & Rural & 118 & 37.5 \\
\hline \multirow[t]{4}{*}{ Marital status } & Married & 163 & 51.7 \\
\hline & Single & 87 & 27.6 \\
\hline & Divorced & 45 & 14.3 \\
\hline & Widowed & 20 & 6.4 \\
\hline \multirow[t]{2}{*}{ Ethnic group } & Amhara & 286 & 90.8 \\
\hline & Tigray & 29 & 9.2 \\
\hline \multirow[t]{2}{*}{ Religion } & Orthodox & 292 & 92.7 \\
\hline & Muslim & 23 & 7.3 \\
\hline \multirow[t]{4}{*}{ Occupation } & Housewife/farmer & 184 & 58.4 \\
\hline & Daily laborer & 64 & 20.3 \\
\hline & Government employ & 35 & 11.1 \\
\hline & Merchant & 32 & 10.2 \\
\hline \multirow[t]{4}{*}{ Educational status } & Can't read and write & 184 & 58.4 \\
\hline & Elementary (1-8th grade) & 74 & 23.5 \\
\hline & Secondary (9-12th grade) & 37 & 11.7 \\
\hline & College and above & 20 & 6.3 \\
\hline \multirow[t]{2}{*}{ Income } & $\leq 608$ & 114 & 36.2 \\
\hline & $609-1258$ & 103 & 32.7 \\
\hline
\end{tabular}




\begin{tabular}{|llll|}
\hline Variables & Frequency & $\%$ \\
\hline & $1259-4992$ & 98 & 31.1 \\
\hline
\end{tabular}

\section{Nutritional status}

The overall prevalence of undernutrition was $85(26.9 \%)$ and the mean BMI was $19.8 \mathrm{~kg} / \mathrm{m} 2 \pm 2.7 \mathrm{SD}$. Twenty-one (6.7\%) of the participants were overweight and 2 participants were obese. Of overall under nourished 44 (51.8\%), were between 25-34 age group and females were 57 (67.1\%). About $312(99.1 \%)$ participants were taking staple diet (Injera with wot = Ethiopians favorite food) three or more times a day. Two hundred ninety-three (93\%) of the study subjects got dietary counseling and two hundred eighty-six (90.9\%) were practiced the given dietary counseling.

\section{Present health status}

About 160 (36.8\%) participants were in WHO clinical stage three followed by stage one 88 (27. 9\%). One hundred ninety-two (61\%) had opportunistic infection. Out these, 54 (17.1\%) developed diarrhea, fifteen $(15.9 \%)$ and $49(15.6 \%)$ were complaining cough and oral thrush respectively. One hundred eighty-nine (60\%) of the participants had eating problems. Of them, 71 (22.5\%) and $67(21.3 \%)$ were complained pain/difficulty of swallowing and loss of appetite respectively.

\section{Factors Associated with under nutrition in PLHIV on ART}

In the logistic regression analysis, under nutrition $(\mathrm{BMI}<18.5 \mathrm{Kg} / \mathrm{m} 2)$ was significantly associated with the duration of ART, WHO clinical staging, eating problems and dietary counselling. Clients on WHO clinical stage three were 12.6 times more likely to be under nourished than those who were in stage four $(A O R=12.6,95 \% \mathrm{Cl} 4.27-37.00)$ and $\mathrm{WHO}$ clinical stage two were three time more likely to be under nourished than those who were in stage four $(A O R=3.0,95 \% \mathrm{Cl},(1.06-8.53)$. The duration of ART was also associated with under nutrition. Patients treated from 6-11 months were five times more likely to be undernourished as compared with those treated more than 24 months and those treated 12-24 month were nearly 7 times more likely to be under nourished as compared to those treated for greater than 24 months (AOR $=6.931,95 \%, \mathrm{Cl} 1.614-29.754)$. There was a statistically significant association between under nutrition and the presence of eating problems ( $A O R=6.4,95 \% \mathrm{Cl},(7.21-15.40)$ ). Dietary counseling was also associated with under nutrition ( $\mathrm{AOR}=0.2,95 \%, \mathrm{Cl}, 0.05-0.781)($ Table-2). 
Table 2

Factors Associated with Under Nutrition of Adult People Living with HIV/ADIS on ART at Health Centers of Achefer Woreda, North West Ethiopia, June 2015.

\begin{tabular}{|c|c|c|c|c|c|}
\hline \multirow[t]{2}{*}{ Variables } & & \multicolumn{2}{|c|}{ Undernutrition } & \multirow[t]{2}{*}{$\operatorname{COR}(95 \% \mathrm{Cl})$} & \multirow[t]{2}{*}{$\operatorname{AOR}(95 \% \mathrm{Cl})$} \\
\hline & & Yes & No & & \\
\hline \multirow[t]{4}{*}{ ART treatment duration } & $<6$ month & 3 & 47 & $\underset{\star \star}{4.1}(1.14-14.66)$ & $3.3(0.76-14.25)$ \\
\hline & $6-11$ month & 18 & 69 & $\underset{\star \star}{6.6}(1.90-22.87)$ & $\begin{array}{l}4.7(1.10-20.35) \\
*\end{array}$ \\
\hline & $\begin{array}{l}12-24 \\
\text { month }\end{array}$ & 29 & 69 & $\underset{\star \star}{12.2(3.50-42.44)}$ & $6.9(1.61-29.75)$ \\
\hline & $>24$ month & 35 & 45 & 1 & 1 \\
\hline \multirow[t]{4}{*}{ WHO clinical staging } & Stage one & 6 & 82 & $\underset{\star \star}{2.3}(0.72-7.21)$ & $1.3(0.34-5.04)$ \\
\hline & Stage two & 7 & 42 & $\underset{\star \star}{5.4}(2.16-13.66)$ & ${ }_{*}^{3.0}(1.06-8.53)$ \\
\hline & Stage three & 33 & 83 & $\begin{array}{l}14.4(7.21- \\
41.34)^{* *}\end{array}$ & $\begin{array}{l}12.6(4.27- \\
36.99) *\end{array}$ \\
\hline & Stage four & 39 & 23 & 1 & 1 \\
\hline \multirow[t]{2}{*}{ Eating Problem } & Yes & 76 & 113 & $8.7(9.09-18.74)$ & $6.4(7.21-15.40)$ \\
\hline & No & 9 & 117 & 1 & 1 \\
\hline \multirow[t]{2}{*}{ Dietary counseling } & Yes & 73 & 220 & $0.3(0.12-0.67)$ ** & $\underset{*}{0.2(0.05-0.78)}$ \\
\hline & No & 12 & 10 & 1 & 1 \\
\hline \multirow[t]{2}{*}{$\begin{array}{l}\text { Practice of dietary } \\
\text { counseling }\end{array}$} & Yes & 70 & 216 & $\underset{\star \star}{0.3}(0.12-0.43)$ & $0.1(0.08-1.03)$ \\
\hline & No & 15 & 14 & 1 & 1 \\
\hline \multicolumn{6}{|c|}{ - Significantly associated variables after fitting multivariable model } \\
\hline
\end{tabular}

\section{Discussion}

Malnutrition (under nutrition) is more common in developing countries, where patients are often not diagnosed or do not initiate ART until they have advanced disease. Worryingly, the HIV epidemic itself may be contributing to food insecurity at a population level [14-15]. Under nutrition and HIV/AIDS are interconnected but introduction of ART reduced the prevalence of under nutrition on HIV/AIDS patients. In this study the prevalence of under nutrition in HIV/AIDS patients who are on ART was $26.9 \%$. Studies 
conducted in Bahir Dar Felege Hiwot Referral Hospital and Gondar referral Hospital of Ethiopia supported this finding with prevalence of $25.5 \%$ \& $27.8 \%$ respectively $[16,17]$. But this study finding is lower than the finding of Botswana Which was 30\% [20] and higher than a study done in Dilla University Referral Hospital (12.3\%) [18] and in Miami, Florida 17.6\% [14]. The difference could be due to time difference.

In this study undernutrition was more likely among participants who had eating problem. This study is agreed with other studies $[16-17,19]$. The other important variable which had significant association with malnutrition was WHO clinical stages. WHO clinical stage II \& III were significantly higher than clinical stage IV for undernutrition. The reason could be that at WHO clinical stage four most of the patients might start ART and due to this they might recovered from malnutrition. The duration of ART treatment increases the risk of getting malnutrition as shown by the statistically significant association between duration ART and increase of the risk of developing malnutrition. A study in Gondar found that the longer the duration of treatment, the lesser the risk of facing malnutrition (38). This is because there will be low risk of diarrhea, vomiting, respiratory tract infections, and increasing CD 4 count as treatment duration increases and improved nutritional status maintained [17].

Descriptively, the proportion of females under nourished in ART care was higher than males, the possible reason could be due to females' poor adherence to ARV treatment, physiological change, lower economic status, cultural influence to the practice of counseling system.

Another important significant variable of under nutrition in this study was dietary counseling. Those patients who had no nutritional counselling were more likely to be undernourished than had counselling. The finding was consistent with studies conducted in Ethiopia (18), and in Uganda (20). This showed that if patients got dietary counselling they can bring change in nutritional status.

\section{Conclusions And Recommendation}

The prevalence of under nutrition was very high among adult PLHIV on ART in this study. WHO clinical staging, duration of ART, eating difficulty and dietary counselling were the predictors to under nutrition. It has been learnt that under nutrition \& its problems in HIV patients are difficult; no single method exists as solution. Hence, there is a rapid need to join together nutritional support with comprehensive HIV care. Dietary counseling was positively associated with good nutritional status.

\section{Abbreviations}

Acquired immunodeficiency syndrome (AIDS), Adjusted Odds Ratio (AOR), Anti-Retroviral therapy (ART), Bahir Dar University (BDU), Body Mass Index (BMI), Confidence interval (Cl), Crude Odds Ratio (COR), Human immunodeficiency virus (HIV), People living with HIV/AIDS (PLWHA), World Health Organization (WHO).

\section{Declarations}




\section{Ethical review}

Ethical approval was obtained from ethical review committee of Institutional Review Board of Bahir Dar Institute of Technology, faculty of chemical and food engineering, department of applied human nutrition, Bahir Dar University. Permission was obtained from Amhara Regional Health Bureau, West Gojjam health department and North Achefere woreda health offices accordingly. Verbal consent was taken from each participant after explained purpose of the study. They were assured their privacy and informed that they can discontinue at any time. Participants were also informed that all the data obtained from them would be kept confidential. Clients identified as under nourished were given nutritional counseling by linking them with the clinician working in ART Clinic.

\section{Consent for publication}

The authors declared that they have agreed to publish on this journal

\section{Availability of data and material}

The datasets supporting the conclusions of this article are included within the article.

\section{Competing interests}

The authors declared that they have no conflicts of interest

\section{Funding}

This research was funded by Bahir Dar University, Institute of Technology, Faculty of Chemical and Food Engineering

\section{Authors' contributions}

MY, YW, YM, SD, TA and GN participated conceived the study, development of the study method, analyzed the data and revised the manuscript. All authors read and approved the final manuscript.

\section{Acknowledgements}

We would like to acknowledge the assistance of Bahir Dar University, Institute of Technology Faculty of Chemical and Food Engineering, Department of Applied Human Nutrition in undertaking this research. We would also like to express our gratitude to study participants and officials working in Amhara Regional state, Achefer Health Office that really deserves acknowledgement for their cooperation. Last not least, our thanks also go to data collectors, supervisors, advisors and participants. 


\section{References}

1. Federal Democratic Republic of Ethiopia. Country progress report on HIV/AIDS; 2012.

2. UNAIDS. Report on the Global AIDS Epidemic; 2013.

3. WHO. Global HIV/AIDS response. Epidemic update and health sector progress towards universal access: progress report; 2011.

4. WHO. Nutrient requirements for people living with HIV/AIDS: Report of a technical consultation. Geneva: World Health Organization; 2003.

5. Lisa Kosmiski. Energy expenditure in HIV infection. The American Journal of Clinical Nutrition. 2011;94(6):1667-76.

6. John R, Koethe, Douglas C. Heimburger.Nutritional aspects of HIV-associated wasting in subSaharan Africa.The American. Journal of Clinical Nutrition. 2010;91(4):S1138-42.

7. Sheri D, Weiser David R. Bangsberg and et' al. Food Insecurity among Homeless and Marginally Housed Individuals Living with HIV/AIDS. AIDS Behav. 2009;13:841-8.

8. CSA. Ethiopian Demographic and Health Survey; 2011.

9. Derek C. Macallan. Clinical Trials for the Treatment of Secondary Wasting and Cachexia. JN the journal of nutrition. 1999;129:238-42.

10. Wanke C.Nutrition and HIV in the international setting.Nutrition in Clinical Care. 2005; 8(1):44-48.

11. De Pee S, Semba and Richard D. Role of nutrition in HIV infection: Review of evidence for more effective programming in resource-limited settings. Food Nutrition Bulletin. 2010;31:313-44.

12. Laurence A, Chantal U, Helena $\mathrm{H}$. and et 'al. Nutrition outcomes of HIV-infected malnourished adults treated with ready-to-use therapeutic food in sub Saharan Africa. Food Nutrition Bulletin. 2010;31(78):287-364.

13. Federal HIV/AIDS. Prevention and Control Office of Ethiopia. Report on progress towards implementation of the UN Declaration of Commitment on HIV/AIDS 2010.

14. Louise C, Ivers; Kimberly A, Cullen; Kenneth A. Freedberg;et' al. HIV/AIDS, Under nutrition, and Food Insecurity. Oxford Journals Medicine Clinical Infectious Diseases. 2009;49(7):1096-102.

15. David LP, Edward AF. Changes in Child Survival Are Strongly Associated with Changes in Malnutrition in Developing Countries. J Nutr. 2003;133:107-19.

16. Wasie B, kebede Y, Yibrie A. Nutritional Status of Adult living with HIV/AIDS. Ethiop. J Health Biomed sci. 2010;3(1):3-14.

17. Molla D.,Fikadu M, Dereje B. Nutritional Status and Associated Factors Among Adult HIV/AIDS Clients. Ethiop J of PublicHealth. 2013;1(1):26-9.

18. Solomon H.,Girma T.,Henok T. prevalence and its associated factors in people living with HIV/AIDS. Ethiop. J. Health Biomed sci.2013,71:13.

19. Nnyp. The risk of developing malnutrition in people living with HIV/AIDS in South Africa. Journal of Clinical Nutrition. 2009;22(2):89-93. 
20. Bukusuba J, Joyce K, Kikafunda, Roger G, Whitehead. Nutritional Knowledge, Attitudes, and Practices of Women Living with HIV. J Health Popul Nutr Eastern Uganda. 2010;28(2):182-8. 